\title{
SOCIO-PSYCHOLOGICAL STUDY AMONG INJECTABLE DRUG USERS IN KATHMANDU VALLEY
}

\author{
Ojha S $\mathbf{P}^{1}$, Pokharel $\mathbf{A}^{2}$, Aacharya $\mathbf{R} \mathbf{P}^{3}$ \\ Pandey $\mathrm{K} \mathrm{R}^{3}$, Bhusal $\mathrm{CL}^{3}$, Marhatta $\mathrm{M} \mathrm{N}^{3}$
}

\section{ABSTRACT}

On the background of ever increasing HIV transmission in our community through various routes, the psychosocial factors related with intravenous drug abuse has become necessary to be studied. Aim of the study was to assess the Socio-psychological factors that influence people to use drugs, especially to use Injectable drugs. We enrolled a sample of 393 Intravenous drug users, all male, in the Kathmandu Valley. Participants were administered a semi structured proforma to assess the psychosocial issues related with the drug intravenous drug abuse. Mean age of the sample was 27.76+ 4.86 years. Majority were single, unemployed, Hindu and by caste Newars, with education more than high school (SLC or more). The first psychoactive substance use by most of them was cannabis. The most frequently used psychoactive substance was injection Buprenorphine (Tidigesic), which was followed by mixture of various substances (opiates, benzodiazepines, antihistamines) and Diacetyl morphine (Brown sugar). Factors associated with the start of the drugs were for enjoyment, friend's pressure and to alleviate mental tension. Many accepted Injectable drug use contributing to problems in mental, marital, social, economic and legal aspects of their life. Despite knowing the harms caused by the drugs majority persist on its use. A needle exchange programme has been viewed positively by many.

Key words: buprenorphin, needle sharing, needle replacement, HIV transmission.

1. Department of Psychiatry, Institute of Medicine.

2. Mental Hospital, Lagankhel.

3. Nepal Medical Association.

Address for correspondence : $\quad$ Dr. Saroj Prasad Ojha, MD (Psychiatry),

Department of Psychiatry, Institute of Medicine

Maharajgunj, Kathmandu, Nepal. 
INTRODUCTION

Use of illicit drugs by the youths is a serious problem faced by our society. It brings about many physical, psychological and social problems. The range of problems from occasional use of a psychoactive substance to the dependent level. Drug use through intravenous route exposes a person to much more health hazards when compared to conventional naso-oral route. Intravenous drug abuse associated with use of already used syringes / needles has been found to be responsible for rapid spread of HIV and other infectious disease in this group of people ${ }^{1}$. The possible explosion of HIV in our community has forced us to think about the possible methods of timely intervention. The 1992 International Classification of Diseases-10 edition (ICD-10) by the World Health Organization ${ }^{2}$ has identified 10 classes of psychoactive substances which lead to mental and behavioral disorders. Similarly, the 1994 American Psychiatric Association's Diagnostic and Statistical Manual, IV edition ${ }^{3}$ also enlists the same classes for psychoactive substances. The study of associated social as well as psychological factors and behavioural patterns associated with intravenous drug abuse will be fruitful in this context.

\section{MATERIAL AND METHOD}

Aim of the study was to assess the sociopsychological factors that influence people to use drugs, especially to use injectable drugs. A questionnaire was developed through the process of intense discussion and was agreed upon to use it in the study. Intravenous drug users were selected on the basis of their presence in various pocket areas of drug abuse in Kathmandu valley. To get exact number of such people is very difficult, thus all consecutive people who abused intravenous drugs and resided in Kathmandu valley were included in the study. Social workers were trained to use the questionnaire and employed to collect the data from people who used intravenous drugs. Informed written consent was obtained from all who were included in the study. Data was entered in SPSS software for windows and analysed in the same.

\section{RESULTS}

\section{Sociodemographic profile}

All of the 393 subjects were males with mean age $27.76+4.86$ years (range $17-40$ years). Majority were in the age group $26-30$ years. Two thirds of the subjects were actually 21 to 30 years of age. Majority were single, Hindu and Newars, closely followed by chhetris. Unemployed (37.2\%) were the largest occupational group. Mean years of education obtained by them was $8.91+3.9$ years. More than $60 \%$ had completed their high school (SLC or more). The average number of the family members was $5.98+2.54$. The average monthly income of the family was N. Rs. 15704+21165 (range $2000-150000$ ). For majority it was in the range Rs. 10000 to Rs. 50000 .

\section{The first drug}

Table I shows that Buprenorphin (Tidigesic) was used as most frequent injectable among all.

Table I

Psychoactive substance

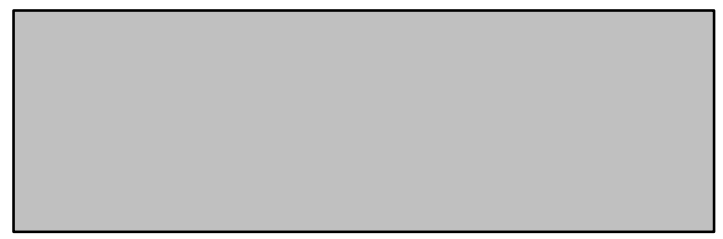

Diacetylmorphine accounted for $18.1 \%$. Mixture of various substances (opiates, benzodiazepines, antihistamines) was used through the parenteral route by $25.4 \%$ subjects. When enquired about the first psychoactive substance ever used, $45.3 \%$ replied as cannabis. Next largest group was those who used Buprenorphin (Tidigesic). Further detail 


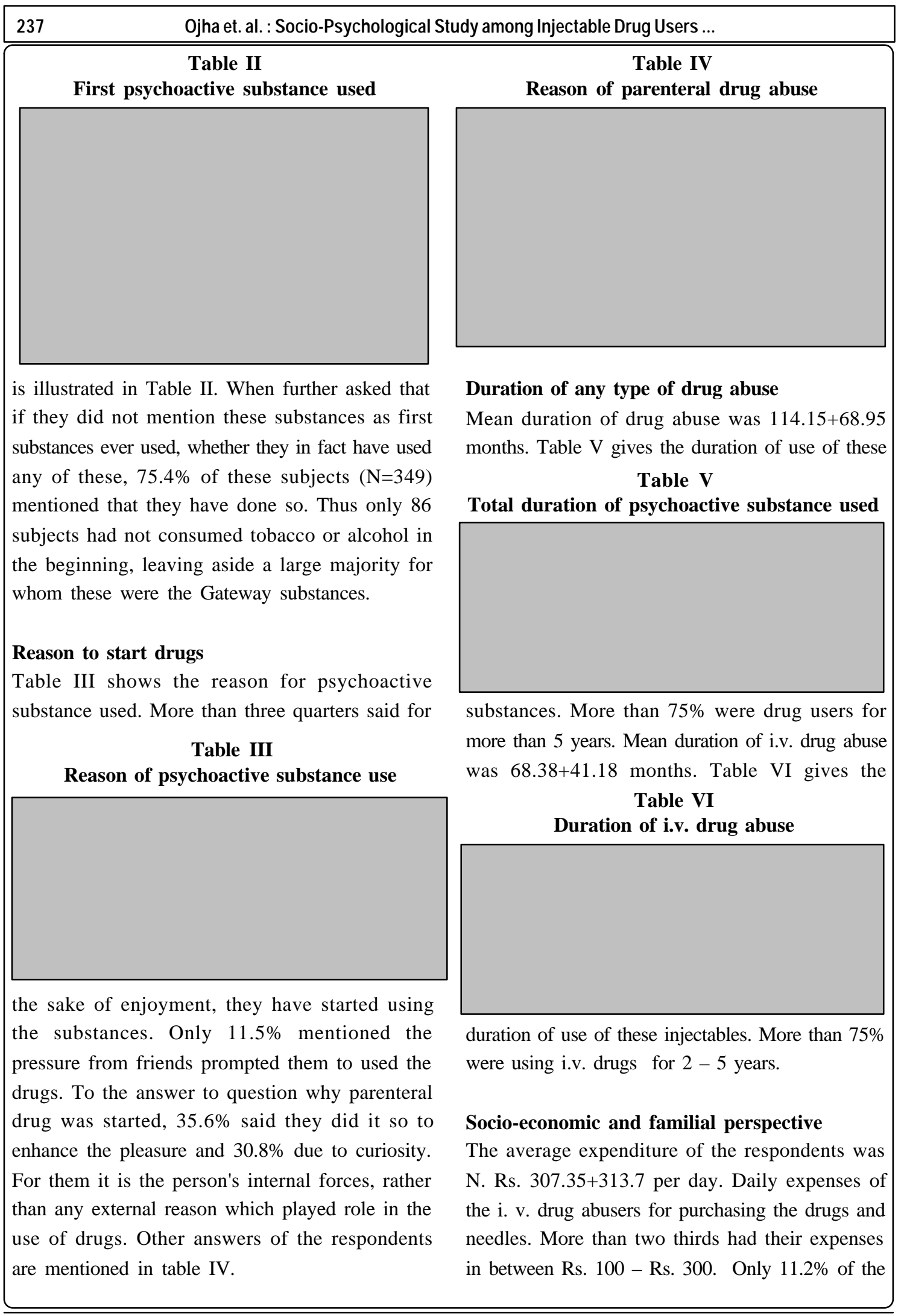

JNMA, January - March, 2002, 41 
subjects mentioned any of their family members abusing drugs. Most frequent reply was siblings. Various types of mental problems were experienced by $55.5 \%$ respondents. These were mainly feeling tense, getting depressed or anxious. Economic problems were faced by $46.6 \%$. and disturbance in marital relationship was experienced by $26.5 \%$. Problems in the social status were experienced by $57.3 \%$. These were mainly in-acceptance in society in various instances, humiliation, and looking at them suspiciously. More than half accepted that they either had legal problems or in police case. Most of these mentioned that they were in police custody for few days mainly due to handling of the drugs or violence in the effect of the drugs.

\section{Knowledge of harm and practice}

A large majority $(72.8 \%)$ said that they know about harmful effects of the drugs used through i.v. route and $35.4 \%$ had suffered problems due to needle use. Much more $(93.9 \%)$ mentioned that they are aware of harms of needle sharing. Despite that, $31.3 \%$ accepted that they share needle. Regarding needle sharing, only $2 \%$ said that they would share needle in all conditions, where as $34.4 \%$ said they will never share needle. Just less than half however said that they would share when they were sure that another person who first has used needle is free of any disease. Just below one fifth said that when they were having withdrawl symptoms and there's no other way, they would share the needle (Table VII). To a hypothetical question that if they have the knowledge that they harbour some

Table VII

If I have to share needle infectious disease and a friend asks for the needle used by them, nobody responded that they would give the needle. Only $5.6 \%$ said that they would not care. Remaining either answered "will not allow" or "advise not to use".

\section{Opinion regarding needle exchange programme}

Majority (81.7\%) supported the needle exchange programme, which exchanges new needle for every used one. However only $24.9 \%$ said that it will promote drug abuse, remaining three quarter mentioning that it will not promote drug abuse.

\section{DISCUSSION}

\section{Socio-demographic factors}

The respondents in the present study clustering below the age 30 years is a verification that this is predominantly a problem of young people. A survey by a NGO in the south Delhi in India identified 307 Injectable drug addicts, majority of them were in the age group 21 to 40 years, literate ${ }^{4}$. Majority being Hindu and Newars is not difficult to understand, when the sample is obtained in the Kathmandu Valley. Absence of females in the study indicates inappropriate sampling.

Business as the major occupation hints towards economic liberty at an earlier age may be related with the use of drug in these people. "Unemployed" has however been noted as the largest group in this category, but it's cause or consequence relation with the drug abuse is not answered in this study. More than $60 \%$ having being completed their high school places majority in the educated group.

\section{Expenses vs. family income}

The average monthly expenditure for purchasing drug and needle, Rs. 9210 (=30* Rs. 307), 58.6\% of the average monthly family income (Rs. 15704). Majority having mentioned being in police custody in the matters related with drugs, the possibility 
that money coming through criminal activities to meet expenses of many must be thought of.

\section{The first drug}

Buprenorphin (Tidigesic) was used as most frequent injectable among all, which was followed by Mixture of various substances (opiates, benzodiazepines, antihistamines) and Diacetylmorphine. This reflects the degree of easiness of availability of the substances in terms of both accessibility as well as cost.

The most important finding is that majority had either started through cannabis or tobacco products or alcohol. The concept that alcohol and tobacco products acting as gateway to more serious habit forming substances suggests that these need to be controlled strictly, if we plan to reduce the newcomers in the habit of substance abuse.

In a prospective study carried out at the Drug Dependence Treatment Center of the All India Institute of Medical Sciences (AIIMS) in Delhi, dependence on injectables was seen in $22 \%$ of the total cases and injection use as part of multi drug use pattern in another $20 \%$ of the cases leading to figure of $42 \%$ for Injectable users. ${ }^{5,6}$

\section{Psychosocial reasons to start drugs}

More than three quarters said for the sake of enjoyment, they have started using the substances. Only a minority mentioned the pressure from friends prompted them to used the drugs. Fewer were those who said that it was due to stress they have started the drugs. Almost similar response was for start of intravenous drugs. Thus for majority, it was the person's internal forces, rather than any external reason which played role in the use of drugs. However those who mentioned that due to friend's influence / pressure they opted parenteral route were almost double as compared to those who started the drugs for the first time. A survey by a NGO in the south Delhi in India, which interviewed 307 intravenous drug abusers, came up with the finding that easy availability and economic considerations were the commonest reason cited by most of these addicts. ${ }^{4}$

A report from Patna, India explored the reasons for drug, particularly buprenorphine abuse. Easy availability, low cost, and purity were the common reasons for such use in the study ${ }^{7}$. Another similar report from the Southern city of Bangalore (NIMHANS) confirmed the rising trends of buprenorphine abuse, with a noticeable shift from heroin to buprenorphine ${ }^{8}$, again due to same reasons.

\section{Duration and possibility of intervention}

Mean duration of drug abuse was almost double as compared to mean duration of i.v. drug abuse. There was difference of almost 4 years in average maintaining ownself in the drug abuse through naso-oral route before switching to the parenteral route. An intervention strategy may be focussed in this interim phase to reduce the harm when we talk about retarding the spread of HIV.

\section{Genetic or psychological influence}

A small minority of the subjects mentioned any of their family members abusing drugs. Most frequent reply was siblings. This finding although prompts us to think about any genetic contribution in drug abuse, this conclusion cannot be drawn at this stage as shared social factors and psychological influence like that of modeling may well be responsible.

\section{Psycho-social consequences of drug} (i.v. and others) abuse

Mental, marital, social, economic and legal problems faced by the subjects clearly indicates deleterious effects of these substances in psycosocial aspects of a person's life. This work has just touched these aspects and in depth study of the psycho-social impact of drugs needs to be studied. 
A need to carry out harm reduction programme Despite a large majority mentioning that they know about harmful effects of the drugs used through i.v. route and much more mentioning that they are aware of harms of needle sharing, $31.3 \%$ of the respondents accepting that they share needle is a dangerous situation. Furthermore about half of the respondents saying that they would share when they were sure that another person who first has used needle is free of any disease is also needs to be evaluated with caution, because the faith may not always pay well to the person who practices this way. Thus a prompt intervention strategy should be discussed regarding this matter. The strategy may be in the form of "needle exchange programme", which has been supported by majority of the subjects of the study. The strategy would operate to halt the rate of spread of HIV transmission, rather than to control the problem of drug abuse. The strategy should be however run parallel with programmes aiming at demand reduction of the drugs.

\section{RECOMMENDATIONS}

- Two level of intervention is suggested

1. to stop the switch from naso-oral route to parenteral route.

2. To reduce the harm of needle sharing both being supplemented by programmes for demand reduction.

- Research to carry out the extent of psychological impact, which further directs the behaviour of the person.

- Programme targeting the "gateway substances" so that the tastes of the evils are not tried from the beginning.

- As majority give the reason not due to the external factors they started the drugs, an "adolescence counseling programme" should be started aiming to help those who are being attracted towards the drugs.

\section{REFERENCES}

1. Desai NG, Gupta DK, Khurshid KA. Substances Use Disorders. Textbook of Postgraduate Psychiatry. 1997; 5: 76-89.

2. World Health Organization. ICD-10 Classification of Mental and Behavioral Disorders: Clinical Descriptions and Diagnostic Guidelines. Geneva: WHO, 1992.

3. American Psychiatric Association. Diagnostic and Statistical Manual of Mental Disorders. IV Ed. Washington DC: APA, 1994.

4. Society for Promotion of youth and Masses. Intravenous Drug Addicts: AStudy in South Delhi Slums. New Delhi: SPYM, 1995.

5. Gupta DK, Desai NG, Kishore C, et al. Pattern of Multiple use in heroin dependent individuals. Abstracts of the $48^{\text {th }}$ Annual National Conference of the I ndian Psychiatric Society, Bangalore. Indian J Psychiatry. 1996 (Suppl); 38: 38-82.

6. Desai NG, GuptaDK, Kishore C, et al. Injection drug use among outpatient sample of drug dependence in Delhi, India. Abstracts of the NI DA Meeting on Building I nternational Research in Drug Abuse, Nashville, USA, 1997, 40.

7. Kumar V, Singh BK. Reasons behind increasing buprenorphine abuse. Abstracts of the $48^{\text {h }}$ Annual National Conference of the Indian Psychiatric Society, Bangalore. Indian J Psychiatry. 1996 (Suppl); 38: 82-83.

8. Umesh SB, Chaturvedi SK. Changing patterns in opiate abuse with a focus on buprenorphine. Abstracts of $47^{\text {th }}$ Annual Conference of the Indian Psychiatric Society, Patna. Indian J Psychiatry. 1995; 37(Suppl): 23.

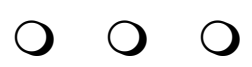

\section{(This study was conducted by Nepal Medical Association with the financial support from WHO and National Centre for AIDS \& STD Control.)}

